\title{
Basic and discovery-based translational research on cancer was on the agenda at the 21st Congress of the European Association for Cancer Research (EACR)* in Oslo, Norway, 26-29 June 2010
}

\author{
Alicia Llorente Martínez • Ingrid Roxrud
}

$\mathrm{O}^{1}$ a beautiful summer day in Oslo, EACR president and conference chair Anne-Lise Børressen-Dale welcomed the nearly 1400 attendants to the 21st EACR Meeting. The president of EACR's "big sister", the American Association for Cancer Research (AACR), the rector of the University of Oslo and the Norwegian Minister of Research and Higher Education joined the EACR president in sharing with us their enthusiasm for the congress. Later that day, the spectacular new opera house in Oslo was the venue for one of the most memorable highlights of the congress, the Opening Lecture and Ceremony. Science and music went hand in hand throughout the evening. The Opening Lecture was given by Sir David Lane, an essential player in identifying and understanding the role of the tumour suppressor p53. But this time Professor Lane held an atypical lecture for this type of congress. Under the title "Stopping Cancer: A Challenge for Science and Society", he addressed the challenges society faces with respect to cancer. He stressed the importance of both prevention and research, and how different groups in society have to work together to fight cancer. The Norwegian Minister of Health and Care Services also participated in the event and sent the following message to the audience: "Let's make the impossible possible!"

\footnotetext{
A. Llorente Martínez (凶) · I. Roxrud

Department of Biochemistry

Institute for Cancer Research

Oslo University Hospital-The Norwegian Radium Hospital

Montebello, 0310 Oslo, Norway

e-mail: aliciaml@ rr-research.no
}

*The European Association for Cancer Research (EACR) has the advancement of cancer research as its guiding aim. It was established in 1968 and today is Europe's largest member society for cancer research. EACR is a founder member of ECCO, the European CanCer Organisation.
Several awards were given during the congress, such as the EACR Cancer Researcher Award to Kevin Ryan at the Beatson Institute for Cancer Research, Glasgow, UK, for his work related to the regulation of cell death in tumour development and cancer therapy, and the Norwegian Cancer Society Young Cancer Researcher prize to Thomas Arnesen from the University of Bergen, Norway, for his work on inhibition of protein acetylation as a strategy for eliminating cancer cells. During a reception at Oslo City Hall, the Cancer Society named Professor Anne-Lise BørresenDale as cancer ambassador for her work on research and cancer awareness both nationally and internationally.

The scientific programme was excellent and presented an outstanding panel of world-class speakers; 108 speakers were on the floor. The programme was organised with all the key features common to past EACR Meetings: plenary lectures, symposia, educational lectures, workshops and of course poster sessions, where over 750 posters were presented (the abstracts can be found in the European Journal of Cancer Supplements, Volume 8, Number $5)$. In addition, the congress introduced the After Sunrise Meet the Expert sessions for the benefit of the early birds. The participants were able to attend lectures on a great diversity of topics related to basic and translational cancer research. The latest developments were presented and subjects such as gene expression and regulation, cancer stem cells, cancer systems biology, angiogenesis, tumour migration, invasion and metastases, cell signalling, epigenetics, canceromics, inflammation and metabolism were widely covered. Some lectures focused on a particular type of cancer, but others on features that are common to many cancer types and can be relevant for several cancer diseases. Highly interactive discussions followed the lectures. In addition to the more result-oriented lectures, the Young Cancer Researcher's Workshop focused on career and grant opportunities for young researchers. Grant opportunities from the European Union, EMBO (European Molecular Biology Organization), Cancer Research UK and the Wellcome Trust were presented. Finally, a Women 
in Science workshop addressed the challenges female scientists encounter.

\section{A taste of the scientific programme}

First on the floor was Elisabeth Blackburn, who together with Carol W. Greider and Jack W. Szostak was awarded the Nobel Prize in Physiology or Medicine 2009 for their work on telomeres and the enzyme telomerase. Telomeres are regions of repetitive DNA at the end of chromosomes that protect them from degradation. Telomeres become shorter when cells undergo cell division due to chromosome replication. This fact limits the number of times a cell can divide and has been related for example to ageing. The enzyme telomerase can restore the length of the telomeres, but it is normally active only in cells that undergo a high number of cell divisions. Interestingly, telomerase is active in most cancer cells and Blackburn discussed the potential therapeutic role of this enzyme in cancer. Furthermore, she presented recent work from her research group where they have identified a mutant telomerase that eliminates cancer cells by inducing telomere fusion. Finally, she elaborated on recent evidence indicating an additional role of this enzyme, thus illustrating the exciting multifunctionality many proteins have.

Epigenetics was another subject that was well covered in the conference. This subject has recently gained importance due to its role in cancer. In a plenary lecture Peter A. Jones from the University of Southern California focused on DNA-methylation of $\mathrm{CpG}$ islands. $\mathrm{CpG}$ islands are often located to promoter regions and after methylation inhibit gene transcription. Whereas most of the $\mathrm{CpG}$ islands in our genome are normally unmethylated, $\mathrm{CpG}$ islands are often hypermethylated in cancer cells. Jones emphasised that cancer cells can be both hyper- and hypomethylated, and that both situations can be important for carcinogenesis. The fact that epigenetic modifications are gradually acquired and reversible provides us with a new approach for cancer therapy. Epigenetic therapy is already a reality in the USA where several drugs have recently been approved for clinical use. Jones specifically commented on the DNA methylation inhibitor 5-Aza-CdR. During the symposium on epigenetics the molecular mechanisms that control DNA-methylation and DNA-methylation of miRNA were discussed. These are exciting times for scientists working in the field of epigenetics and recent technological developments now make it possible to study the entire epigenome.

The tumour suppressor genes BRCA1 and BRCA, known to be related to hereditary breast and ovarian cancer, were mentioned in three of the plenary lectures. MaryClaire King from the University of Washington, USA, identified BRCA1 and BRCA2 and related them to hereditary breast cancer. In her talk she discussed the challenges associated with genetic testing for hereditary breast and ovarian cancer. There are several factors that make it difficult to identify women with a predisposition to these cancer types, for example the large number of different BRCA1 and 2 mutations, and the large number of patients with mutations in BRCA1 and 2 that do not have close relatives with ovarian and/or breast cancer. King's group has recently developed an assay based on next-generation sequencing to detect all mutations in 21 genes associated with hereditary ovarian and breast cancer. She stressed that even though this type of analysis can improve today's genetic testing, there are challenges related to the use of this method on a large scale. David M. Livingston (receiving the 2010 Carcinogenesis Award) from Harvard Medical School, USA, presented in his lecture the complicated functions of the protein products of these two genes, which are important to maintain the integrity of the genome in several ways. Thomas Helleday (this year's Carcinogenesis Young Investigator Awardee) from Oxford University, UK, talked about the role of BRCA proteins in DNA repair. His work on characterisation of poly(ADP-ribose) polymerase (Parp)'s role in DNA repair has been essential for discovering that Parp inhibitors can selectively kill cancer cells that lack functional BRCA1 and 2. Finally, Helleday also presented recent work showing that 6-thioguanine can also selectively kill cells lacking BRCA2, even in cases where resistance to Parp inhibitors has developed.

Soon after the conference was over it was possible to read on the EACR's webpage that more than three quarters of the participants considered the conference overall to be either 'very good' or 'excellent' and that the conference achieved a $99 \%$ satisfaction rating. In addition, a new record of participants was achieved. Congratulations to the EACR for this result. We warmly recommend cancer researchers to join the next EACR Biennial Congress: EACR-22, to be held in Barcelona, Spain, 7-10 July 2012. 